\title{
Journalism, Pluralism, and Diversity
}

\section{Karppinen, Kari Eerik}

de Gruyter

2018-05

Karppinen , K E 2018 , Journalism, Pluralism, and Diversity . in T P Vos (ed.) , Journalism .

Handbooks of Communication Science , no. 19 , de Gruyter , pp. 493-510 . https://doi.org/10.1515/9781501500084-

http://hdl.handle.net/10138/235983

https://doi.org/10.1515/9781501500084-025

submittedVersion

Downloaded from Helda, University of Helsinki institutional repository.

This is an electronic reprint of the original article.

This reprint may differ from the original in pagination and typographic detail.

Please cite the original version. 
This is a preprint of a chapter to be published in T. Vos (ed.), Journalism, Vol. 19 in De Gruyter Mouton Handbook of Communication Science (HOCS). Berlin: De Gruyter. https://www.degruyter.com/view/product/448266

\section{JOURNALISM, PLURALISM AND DIVERSITY}

Kari Karppinen, University of Helsinki, kari.karppinen@helsinki.fi

The ideal that journalism should reflect different interests and values in society, and provide access to the widest possible range of voices is broadly shared among journalists, researchers and other media critics. The acknowledgement of pluralism and diversity, in different guises, can also be easily found in a variety of media policy declarations as well as ethical and professional guidelines of journalism.

Despite their prominence in debates on journalism, the exact meaning of pluralism and diversity as either analytical or normative concepts in media and journalism studies remains contested (see e.g., Karppinen 2013; Napoli 1999; Raeijmaekers and Maeseele 2015; Valcke, Sükösd, and Picard 2015). Beyond general calls for plurality and diversity in journalism, the concepts can be used at a variety of levels, ranging from the structure and ownership of media, through the demographic diversity of the journalistic workforce, to the selection and framing of individual news stories. Pluralism and diversity are also attached with different meanings in different contexts: the notions can be used to refer to the relationship of journalism to questions about cultural diversity and minority groups, about political pluralism, or even broader questions about the distribution of power in journalism and society. 
Even if pluralism and diversity are principles that few oppose in principle, there is no general agreement on what exactly makes journalism diverse and pluralistic, and what institutional preconditions these ideals entail. Diverse public speech can be seen as a central element of the freedom of speech - either as a corollary of a free media system or as a necessary precondition for citizens' effective use of their free speech. At the level of media policy and broader political debates on the role of media, however, there are enduring disagreements on whether free market competition between media outlets best satisfies the institutional preconditions for diverse journalism, or if a genuinely representative and pluralistic journalism also requires regulation or public support for certain types of media.

While media policy and regulation are usually concerned with structural questions about media markets and institutions, at the level of journalism practice, there are equally complex questions about what diverse journalism actually involves: Should journalism aim to mirror existing social and cultural differences in society as closely as possible? To what extent does journalism also construct these differences? Or should journalism aim for a more radical role of specifically promoting new viewpoints and perspectives that question existing truths and established structures of power? And what implications do these questions have for journalists' selection of sources, the framing of issues, and other practical decisions that have an impact on whose voices get access to the public sphere?

Furthermore, it can be asked if pluralism and diversity should even be concerns in the digital age, when journalism is allegedly losing its traditional 
gatekeeping role, and new digital platforms add new voices and information sources to the media landscape.

While pluralism and diversity are notions that almost anyone can embrace, on closer analysis, it becomes clear that they are not neutral or unproblematic ideals in journalism. Invoking pluralism and diversity does not in itself provide any simple criteria for assessing the performance of journalism in society. Instead, I argue in this chapter that different interpretations of these notions are inevitably tied to different normative ideas about the role of media organizations and journalism in society.

The chapter begins with a brief introduction to the concepts of pluralism and diversity and their uses and definitions in journalism and media studies. After this, different normative frameworks and levels of analysis in debates on journalism, pluralism and diversity are reviewed. Finally, the chapter addresses some ways in which the internet and the current digital transformations have challenged the thinking about pluralism and diversity in journalism. The basic argument put forward is that if pluralism and diversity are to serve as meaningful concepts with critical force in the context of journalism, and not only as empty catchphrases, the discussion must go beyond counting the number of outlets or content choices available for consumers. Instead, critical research on pluralism and diversity must acknowledge the underlying fundamental questions about the role of journalism in the distribution of communicative power and voice in the public sphere.

\section{Defining pluralism and diversity}


The terms "pluralism" and "diversity" have both several different meanings in social sciences and philosophy. Often the notions tend to be used almost as synonyms, which raises questions about the relationship between the two concepts. In general terms, diversity can be understood as a descriptive term that refers to variety and heterogeneity in whatever field. This can involve cultural, demographic, religious, or political diversity, or in the field of journalism, the diversity of news outlets, content options, or people working within the media. In principle, such diversity can be seen as desirable or problematic, depending on the context.

Pluralism implies a general positive attitude towards diversity, but as an "ism", it a much more complex and politically loaded term. In political philosophy, for instance, pluralism can stand either for the empirical fact that different people hold different beliefs and values, or for the normative view that such diversity is desirable. As a philosophical principle, pluralism can also refer more broadly to "value pluralism" or "ethical pluralism", the idea that values cannot be reduced to a single hierarchy, but are irreducibly multiple and often incommensurable (e.g. Crowder 1994).

Especially as a political value, different theorists emphasize different aspects and have diverging views on how pluralism is best realized. In political theory, the term "pluralism" has traditionally been associated with a specific school of political theory, developed by authors such as Robert Dahl (1956), that described and justified a political system where power is broadly dispersed and a wide array of groups compete over political influence. Similarly, "pluralist" views of media and journalism are often equated with perspectives that defend existing market-based media systems and policies as more or less functional for 
democracy, social stability and consumer choice (Freedman 2008: 30-31). Among critical scholars, this liberal functionalist understanding of pluralism has been widely criticized for its naïve assumptions about political and media power, and for ignoring real, structural inequalities between social groups in terms of their access to the media and the public sphere (e.g. Curran 2002; Freedman 2014). However, over the past decades the concept of pluralism is said to have undergone a renaissance in political philosophy, so that it can be invoked widely and in a broadly positive manner by a variety of social and political theorists, liberal and radical alike (e.g. McLennan 1995).

As McLennan (1995) notes, pluralism is therefore best treated not as a proper "ism" or a distinctive school of thought, but as a concept in the social sciences that raises a series of problems that can apply to a range of different fields. Accordingly, in the context of journalism, these problems can relate to a wide range of issues, concerning the ethical principles used to assess journalism, the distribution of power in journalism, or the diversity of journalistic output. Some associate the terms pluralism and diversity above all with questions of cultural identities or minorities, and ground their discussions in debates on multiculturalism and ethnic diversity (Glasser, Awad, and Kim 2009). In journalism practice, "diversity" often functions as a catchword for issues related to race and ethnicity, either in news coverage or employment. Others who are more concerned with the range of political views and the conditions of public debate more broadly, instead ground their approaches in democratic theory and the metaphors of the free marketplace of ideas or the public sphere (Karppinen 2013). 
While there are no generally agreed definitions of pluralism and diversity in journalism and media studies, in practice the concepts have gained different more or less established meanings in different political and academic contexts (see Karppinen 2013; Valcke, Sükösd, and Picard 2015). In media policy debates, for example, the concept of "media diversity" is more prevalent in the United States, whereas "media pluralism" has become a central concept in European media policy debates.

Some scholars also make a distinction where media pluralism refers specifically to media ownership or market structures, while diversity is used in relation to media contents (Hitchens 2006). No clear definitions, however, have been firmly established, so both concepts thus continue to be used in different meanings, both descriptively and normatively, depending on the context.

In this chapter, I assume a rough conceptual hierarchy whereby diversity is understood in a more neutral, descriptive sense, as heterogeneity at the level of media contents, outlets, ownership or any other aspect deemed relevant; whereas pluralism, as a broader socio-cultural and evaluative principle is understood as the acknowledgement and preference of such diversity, which also requires some schematization of its relationship to democracy or other societal values (Karppinen 2013). In other words, I use the concepts of diversity or plurality primarily in a more empirical sense, while pluralism, as an "ism", refers more explicitly to a normative orientation that considers multiplicity and diversity in in journalism a value (see also Raeijmaekers and Maeseele 2015).

\section{What kind of pluralism and why?}


In line with the broader revival of pluralism in social and political theory, it can be argued that concepts and theories around journalism and society have taken a pluralist or anti-essentialist turn in recent decades. Besides philosophical currents, this prominence reflects real-world historical transformations, such as increased cultural diversity in many countries, as well as changes in the media environment, including the proliferation of journalistic platforms, genres and styles. As normative judgements based on journalistic "quality", "truth" or "common good" have become increasingly problematic, definitions of public interest in the context of journalism have shifted even more towards emphasizing pluralism and diversity.

As John Keane (1999: 3) notes, normative questions about either the structure and organization of media or the quality of their contents, are hard to answer with anything but platitudes about the need for diversity and variety.

The wide and conflicting spectrum of available criteria for deciding what counts as quality pushes towards pluralist conclusions - towards a policy of 'letting hundreds of flowers bloom'. This has the paradoxical effect of encouraging audience segmentation, still further growth in the quantity of media possibilities and outputs, and yet more disputes about whether the effects are more or less pluralistic, more or less in the public interest. (Keane 1999: 8-9)

This inherent ambiguity of the notions raises legitimate questions of whether media pluralism and diversity really amount to anything more than an empty catchphrase. As Denis McQuail (2007: 42) notes, arguments for pluralism 
or diversity "sound at times like arguments on behalf of virtue to which it is hard to object" - yet the inclusiveness and multiple meanings of the concepts also expose their limits, so "we should perhaps suspect that something that pleases everyone may not be as potent a value to aim for and as useful a guide to policy as it seems at first sight". Similarly, Raeijmaekers and Maeseele (2015: 1043) argue that "as a buzzword or as a decontextualized taken-for-granted concept [...] it is generally unclear what is meant by referring to pluralistic media content or how pluralistic media should operate within Western democratic societies."

To a certain extent, the value of pluralistic journalism for democracy and the public sphere is self-evident. Beyond the general consensus that journalism should be inclusive of different voices, however, the implications of pluralism as a normative principle for journalism remain controversial.

While all agree in principle that a wide range of social, political and cultural values, opinions, information and interests should find expression through journalism, does that imply that all views are equal? Is more diversity always better? And are there perhaps limits to diversity? As McLennan (1995: 83-84) notes, it may seem that all things plural, diverse and open ended are automatically to be regarded as good. But in deconstructing the value of pluralism, we are faced with questions of the following order: Is there not a point at which healthy diversity turns into unhealthy dissonance? Does pluralism mean that anything goes? And what exactly are the criteria for stopping the potentially endless multiplication of valid ideas?

Behind the conceptual ambiguity and different definitions, debates on journalism, pluralism and diversity involve genuine normative and political 
contradictions that reflect different normative assumptions about the role of journalism in society.

One of the enduring questions is whether journalism should reflect the prevailing balance of views in society as neutral transmitters of existing identities and differences in society, or whether it is the task of journalism to question the existing socio-political order and introduce new perspectives that challenge the prevailing structures of power (Raeijmaekers and Maeseele 2015: 1047).

Denis McQuail (2007: 49) has distinguished between four normative frameworks associated with diversity: (1) reflection, which means that journalism should reflect proportionately the existing political, cultural and other social variations in society in a proportionate way; (2) equality, which means that journalism should strive to give equal access to any different points of view or any groups in society, regardless of their popularity; (3) choice, which equals diversity with the range of available choices (between outlets, programs, etc.) for individual consumers; and (4) openness, which places emphasis on innovation and difference, valuing new ideas and voices for their own sake.

Each framework implies a different interpretation of pluralism and different standards by which diversity should be assessed in journalism. With all of these perspectives, however, further problems arise from the question of how to identify relevant groups or perspectives that require representation, or how to make decisions on which groups or perspectives are considered innovative or under-represented.

Research on the connections between journalism and community characteristics or demographics has indicated that journalistic reporting tends to 
mirror, at least to some extent, existing societal variations and patterns in public opinion (e.g. Pollock 2013). The idea that individual media institutions or even the media systems could somehow proportionately, or objectively correspond to existing differences in society, however, is easy to denounce as naive. From a critical and constructivist point of view, journalism never only mirror features of reality, but also constructs and frames the issues that it covers (Raeijmaekers and Maeseele 2016).

On the other hand, the alternative of conceptualizing pluralism in terms of openness to any and all ideas raises equally difficult questions about relativism and indifference to journalistic standards of truth, balance and rationality. Especially in the context of an increasingly complex media landscape, where lines between journalism and other types of content are increasingly being blurred, the crucial question remains how pluralism should be conceptualized as a journalistic and political value without falling into an unquestioning acceptance of "anything goes". As McQuail (2007: 43) puts it, "it is possible to have more diversity, without any more of what we really value".

Different normative frameworks may often be in contradiction with one another (see van Cuilenburg 1998). Reflective diversity can mean less diversity in terms of equality or openness, since the idea of representation is usually based on the existing balance of forces in society, and thus tends to affirm existing power arrangements and reinforce the status quo in terms of marginalized and excluded voices. It is in that sense that mainstream journalism is often criticized for offering a plurality of views "within the box", only within certain ideological limits that preserve the status quo of existing social consensus (e.g. Glasser, Awad, and Kim 2009; Raeijmaekers and Maeseele 2016). This mirrors a broader 
political philosophy criticism of conventional liberal pluralism, which, despite its emphasis on diversity, is seen to ignore structural inequalities between groups and individuals (Connolly 1995: xiv). In line with this criticism, journalism that aims to reflect existing political or social perspectives can be seen as giving too much priority to power relations already established, and systematically silencing or ignoring voices of difference and new forces of pluralization (Karppinen 2013).

Different frameworks for conceptualizing the relation between journalism and pluralism can also be paralleled with different views of democracy and different normative theories of journalism and society (see, e.g., Christians et al. 2009; Karppinen 2013; Raeijmaekers and Maeseele 2015).

From the traditional liberal-individualist perspective, pluralism and diversity are often discussed from the perspective of the metaphor of "the free marketplace of ideas", which assumes that through competition and free choice, journalism eventually responds to consumer demand and acts as free and neutral transmitter of individuals' and groups' divergent needs and views (e.g., Napoli 1999; Raeijmaekers and Maeseele 2015: 1044). Such assumptions of the "free information flow", however, are often criticized by critical theorists and critical political economists for failing to account for the relations of power, unequal opportunities open to different social actors, and ways in which communication markets and journalistic practices themselves privilege some voices and exclude others (e.g. Baker 2007).

Instead of reducing questions about pluralism and diversity to satisfying individual consumers' needs, much of the critical academic discussion on pluralistic journalism has been grounded in versions of deliberative democracy 
that draw on Jürgen Habermas's $(1989,2006)$ notion of the public sphere. From this perspective, the role of journalism is not only to satisfy individual consumers but also to promote rational public debate and the formation of a reasoned public opinion. The deliberative model can be seen to relate to the "facilitative role" of media, which holds that journalism should not only report on issues, but also take a role in strengthening and stimulating public life and democratic deliberation (Christians et al. 2009: 158).

While this gives journalism a strong normative basis as a forum of rational public debate, the deliberative approach and its theoretical background have also attracted criticism in both political theory and media studies. Reflecting the renewed emphasis on pluralism and difference in social and political theory, deliberative models of democracy and the public sphere have been criticized for over-emphasizing social unity and rational consensus. The "radical-pluralist" or "agonistic" critics of the deliberative model argue that the emphasis on rational deliberation too ignores unequal relations of power, the depth of social pluralism, and fundamental value differences in society (e.g. Fraser 1992; Mouffe 2005; Wenman 2013; Young 2000).

Instead, radical-pluralists tend to emphasize the value of dissent and contestation, conceiving journalism as a site for political struggle and conflict instead of a site for the formation of common will or consensus (see Carpentier and Cammaerts 2006; Raeijmaekers and Maeseele 2015; Karppinen 2013). Rather than idealizations of balance or representativeness, the primary value guiding the evaluation of journalism from this perspective would then be to challenge the boundaries of consensus and promote exposure to critical voices and views that otherwise might be silenced in public debates. It is much in this 
sense that James Curran (2002: 236-237) argues that rather than the traditional justifications of free competition of ideas or open rational-critical debate, pluralism in the media should be conceived from the viewpoint of contestation of power that different social groups can openly enter. As Christians et al (2009: 126) note, "the radical role" of journalism "focuses on exposing abuses of power and aims to raise popular consciousness of wrongdoing, inequality, and the potential for change".

This is by no means an exhaustive list of different normative positions regarding the relationship between journalism and pluralism. Beyond democratic theory, diversity can also be valued for many other reasons, ranging from economic innovation to cultural toleration, or perhaps even as values in themselves. The point here is that the implications of pluralism as a value orientation for journalism are not as self-evident as one might assume, based on the frequent uses of the concept in professional and academic debates.

\section{Levels of analyzing diversity}

Given the ambiguity and many meanings of the concepts, how can we analyze existing plurality or diversity in journalism empirically? To serve as meaningful analytical notions, many scholars have argued that concepts of pluralism and diversity need to be infused with a more specific and concrete meaning (see Napoli 1999; Valcke, Sükösd, and Picard 2015). As is the case with many other broad journalistic values, such as freedom, independence, or objectivity, attempt to transfer the debate from abstract ideals to the level of analyzing journalistic institutions or performance involves many contradictions. 
As analytical notions, diversity in media and journalism can be analyzed on several levels, ranging from the macro-level of media structure and ownership to the micro-level of individual news stories or editorial choices. Several scholars have attempted to break down the analytical levels at which diversity can be examined or empirically measured (see e.g. Napoli 1999; Sjøvaag 2016; Valcke, Sükösd, and Picard 2015). In principle, these can be broken down to an almost endless number of different aspects and dimensions from ideological, demographic or geographic diversity to the diversity of news outlets, sources, viewpoints, genres, representations, opinions, languages, styles, formats or issues covered.

In one of the most frequently cited classifications, Philip Napoli (1999) makes the basic distinction between source, content and exposure diversity, with each having multiple subcomponents.

Source diversity reflects the established media policy goal of promoting a diverse range of information sources or content providers. Also called structural diversity, this includes questions of media ownership, number of outlets in the market, and various other dimensions of organizational or economic structures (e.g. public, private, non-profit media). Besides the general framework conditions of a pluralistic media system, a variety of organizational factors, such as editorial and management policies and newsroom cultures, also clearly impact diversity (Sjøvaag 2016). Structural diversity can be conceptualized, for example, in terms of recruitment and people working within media organizations. Furthermore, assuming that sources and experts who interpret issues and events for the public also enjoy considerable power in framing journalistic coverage, the 
selection of sources by news organizations is also one major structural component of diversity (e.g. Dimitrova \& Strömbäck 2009).

Content diversity refers to another established ideal of journalism, namely the diversity of ideas, viewpoints or content options in the actual output of either the media system or one outlet, which can again be measured on almost any criteria, such as issues, subjects or viewpoints. Here a distinction is often made between external diversity, which refers to the diversity across media outlets, and internal diversity, which refers to the diversity of perspectives within one media organization. External diversity thus implies that number of media organizations that each represent a particular point of view, while internal diversity within one journalistic outlet relates more to the journalistic ideals of balance and fairness.

The problem, again, is that content diversity is difficult to measure in any straight-forward manner. Analyzing the diversity of journalistic output can involve, for example, counting space given to different issues, political parties or candidates, or the representation of gender, minorities, or any other aspect deemed interesting. The methods used to undertake analyses of content diversity often involve rough quantitative content analyses, such as counting heads or measuring the space dedicated to specific issues or positions. However, more elaborate and theoretically developed measures have also been developed that aim to evaluate, for instance, the ideological diversity of voices or news frames and the factors that contribute to make news more "multi-perspectival" (e.g. Benson 2013; Raeijmaekers \& Maeseele 2015).

The third aspect identified by Napoli is exposure diversity, or diversity of use, which refers to the range of content that people actually consume. While 
much of the debate on pluralism and diversity has traditionally focused on questions of market structure, media ownership, or the contents of journalism, the contemporary media environment increasingly raises the question as to whether diversity should refer to the information that is potentially available or to the information that citizens actually access and use (Gibbons 2015; Helberger 2012; Napoli 2011).

From the perspective of the role of journalism in democracy, the point of diversity is not only to provide choice for consumers but also to promote exposure and dialogue between conflicting viewpoints. Traditionally, the assumption has been that greater source diversity will lead to enhanced content diversity, which in turn is thought to promote diversity of exposure as audiences have a greater range of options to choose from. In the contemporary media environment, however, this assumption has increasingly been called into question. It has been suggested that greater choice, and the influence of selective exposure, personal recommendation systems, and "filter bubbles", may actually narrow the range of sources and different viewpoints to which people are exposed. Even though users have an almost unlimited array of content at their fingertips, it has been feared that audiences are increasingly exposed only to a narrow spectrum of the subjects that interest them most, in effect reinforcing rather than challenging their own personal prejudices (Pariser 2011; Sunstein 2007).

From the perspective of citizens' exposure to diverse perspectives and viewpoints, the understanding the dynamics of how source and content diversity impact the diversity of exposure is clearly one crucial question for research. While no one can be forced to consume diverse content, it seems clear that with 
the continued growth of various social media platforms as sources of news, aspect of exposure diversity such as questions of user competences, the effect of algorithmic filtering of information, and the impact of global "superplayers" such as Google and Facebook will receive increasing emphasis in debates on journalism, pluralism and diversity (see e.g. Napoli 2015; Sjøvaag 2016).

In general, some of the most controversial aspects in the debates on pluralistic and diverse journalism concern the relationships between these different components and levels. Denis McQuail (2007: 52) notes that much of the research on pluralism and diversity in the media has been descriptive, with reference to either the content supplied by the media or the structure of ownership and markets, and as such it has not contributed greatly to explaining the causes or consequences of more or less diversity or the relationships between its different aspects.

Does diverse journalistic staff produce more diverse news? Or does ownership of a news outlet influence the daily editorial decisions? In media policy, for example, policies designed to enhance structural plurality, such as limits on media ownership concentration, are not implemented purely for the sake of themselves, but they usually assume that concentration limits the number of voices that have access to the media, and a plurality of sources leads to a greater diversity of media content, which in turn has been presumed to lead to greater exposure diversity (Napoli 1999: 14). This assumption makes it crucial to analyze how market structures and media ownership are related to the range of voices that have access to the public sphere and ultimately to what people actually see and hear. Despite all the discussion on whether and in what way changes in industry structure affect diversity, the problem is that it remains 
difficult to empirically establish any uncontested causal relationships between ownership and content, let alone other dimensions of diversity (Baker 2007; Picard and dal Zotto 2015).

As much as by lacking empirical evidence, however, the ambiguity is also explained by the confusion stemming from the use of different conceptual approaches and normative frameworks. Given the many dimensions of these concepts, it is difficult to design empirical studies that take into account all these aspects and demonstrate any universal causality between them (Karppinen 2015). Attempts at a systematic definition of pluralism and diversity are further complicated by the seemingly contradictory or even paradoxical relationship of its different aspects to one another. Attempts to promote one form of diversity may undermine other forms of diversity. An increase in the choices available to consumers does not necessarily mean that journalism serves minorities better or provides access for alternative and innovative voices. Increasing competition in the media market or new technological possibilities can lead to more diverse media content or further homogenization, depending on the perspective.

There are many questions concerning the influence of ownership, diversity of journalistic workforce, or journalistic routines and practices that all remain relevant objects of study in their own right. Undoubtedly, more research is also needed on the relationship between these aspects and the dynamics of different factors that contribute to a pluralistic and diverse journalism (see, e.g. Benson 2013; Pollock 2013; Sjøvaag 2016; De Vreese, Esser, and Hopmann 2017). In the end, however, what constitutes pluralistic and diverse journalism is not only an empirical question. Understood as a broader normative and social value, pluralism can be seen as an example of an "essentially contested concept" 
(Karppinen 2015), whose interpretations also remain inherently political and dependent on different normative conceptions of the role of journalism and media in society.

\section{The internet and unlimited diversity?}

Besides normative and philosophical problems associated with pluralism as a social value, the growth of digital media and the transformation of the technological and economic environment of journalism is obviously another key factor that has forced researchers to reconsider the meaning and relevance of diversity and pluralism in journalism. With the almost infinite range of information available online, it is often claimed that the internet and new digital media are making the traditional analytic and normative perspectives to pluralism and diversity increasingly obsolete.

On the one hand, the eroding business models of traditional journalistic media organizations and the declining number of journalists have led to fears for the future of professional journalism, and its ability to provide diverse coverage (Boczkowski 2010; Curran et al. 2013; Fenton 2010). On the other hand, in both academic and popular discourse many have celebrated digital media as tools that will inevitably lead towards democratization and decentralization of the public sphere and to the emergence of new voices (e.g. McNair 2006; Castells 2009).

In the digital environment in which journalists now work, new facts are being unearthed daily; more audience feedback is being integrated; more voices are being heard; more diverse perspectives on the same news 
stories are being presented; more stories are available, archived and searchable for longer periods of time; more men and women of power are being watched more closely; and more people are engaged more actively with the changes in the world-by taking photos or making videos of key moments, by commenting on blogs, or by sharing the stories that matter to them. (Van der Haak, Parks, and Castells 2012: 2923)

With more information available in public than ever before, concerns for media pluralism and diversity appear to have become not only increasingly contested, but for some, analytically obsolete or anachronistic. In what sense is it then meaningful to speak of pluralism when media systems in general are characterized more by abundance than scarcity?

The worries over pluralism and diversity in journalism largely stem from the assumed power of journalism as a powerful gatekeeping institution of public communication flows. It is this role that makes it crucial to interrogate the openness of journalism to different voices, ideas and interests in society. Concerns over the concentration of media ownership or editorial balance or bias, only makes sense if it is assumed that journalistic organizations hold meaningful power.

With the shift to a digital media environment, it is often assumed that the control over communication is shifting towards individual users, as audiences can increasingly filter and personalize information and choose how, when and where information is received. Rather than meaning the end of powerful intermediaries and gatekeepers though, the new environment also presents new 
forms of scarcity and new ways in which the flows of information are being controlled and shaped (e.g. Napoli 2015; Vos \& Heinderyckx 2015)

In some ways, the new forms of concentration, exclusion and hierarchies online go even deeper than those in traditional media. According to many critical voices, the internet and new forms of online journalism have done little to broaden political discourse or alleviate the concentration of media power in the hands of few actors that strongly shape the way that news online is presented and accessed (Curran, Fenton, and Freedman 2013; Hindman 2009; McChesney 2014). Curran et al. (2013: 887), for instance, note that leading websites around the world largely reproduce the same kind of news as legacy media, favoring the voices of authority and expertise over those of campaigning organizations or ordinary citizens.

Some of the ways in which online information is filtered are familiar and due to the enduring presence of old media organizations online, while other aspects of online filtering, like the "algorithmic gatekeeping" conducted by search engines, social media platforms, and other recommendation systems, are new and less researched from the perspective of pluralism and diversity (Napoli 2015). In many ways, search and social media platforms perform a function comparable to that of traditional journalistic gatekeepers, by preselecting the information available to users based on their previous choices and friends' recommendations. As a consequence, journalism researchers now increasingly recognize also how algorithms - and the corporations that own and design them - shape also journalistic values and processes (e.g. Diakopoulos 2015; Napoli 2015). 
Despite all the rhetoric of diversity, plenitude and complexity, the concerns over the concentration of power and the homogenization of content have not disappeared in the digital age. Instead, concerns over pluralism and diversity have only acquired even more dimensions. What implications do automated journalism and robot reporters, for example, have for diverse journalism (Diakopoulos 2014)? Is there a need for "diversity sensitive design" of new journalistic platforms? How could algorithms and recommendations systems that increasingly shape exposure to news be designed to stimulate diverse exposure to different viewpoints and perspectives (Helberger 2011)?

All in all, it is clear that new technologies and their implications for diverse journalism can be interpreted in widely different ways, depending on the normative perspective from which one approaches pluralism and diversity.

From the perspective of journalism research and practice, it has been emphasized that instead of simply analyzing what is produced or what is available, a greater emphasis needs to be put on users' engagement with different platforms and news sources and questions of who actually participates and in what ways (Aslama Horowitz and Napoli 2014, Gibbons 2015). As the logic of exclusivity is shifting from production to the selection and filtering of information, it can be argued that researchers should also focus more on the ways in which citizens find and access news and information. On the other hand, the new environment also implies new demands on journalists. Instead of isolated gatekeepers, journalists can increasingly be seen as curators, or nodes in a network that collects, processes, and distributes, and seeks to make sense of the information abundance (e.g. Van der Haak et al. 2012). 
From the perspective of pluralism as a broader societal value, however, the emphasis on user competences and new journalistic tools and practices is not enough. If they are to serve as critical concepts, I argue that debates on pluralism and diversity must also acknowledge questions about the enduring role of journalism and other media with regard to the distribution of communicative power and influence in society. New technologies and communicative abundance has not diminished the fact that some actors and groups have more communicative power and political, economic or symbolic resources to get their voices heard than others. From a broader normative perspective, the challenge is therefore to elaborate a conception of pluralism that helps us to perceive and evaluate these developments in contemporary journalism.

\section{Conclusions}

Despite all the promises, the internet and other new technologies are not able to resolve once and for all the asymmetries of communicative power between different social actors or the worries over concentration of power in the hands of few actors. Instead, new forms of concentration, control and gatekeeping have brought about new concerns, highlighting the nature of pluralism and diversity as values that do not have a final solution, but which constantly create new dilemmas and challenges for journalism.

Pluralization and homogenization are forces that simultaneously affect journalism, regardless of its technological form. Journalism can challenge existing truths and empowers new voices, but also homogenize cultures, 
reinforce existing power relations, and generate social conformity. The balance of these forces varies in different contexts and setting, but these dynamics cannot be reduced to the effects of technological development, media ownership, or any other single determinant.

The concepts of pluralism and diversity in journalism do not have a universal meaning, nor do they provide a neutral yardstick for assessing journalistic performance across different cultural and institutional contexts. Instead, pluralism and diversity can signify radically different, often contradictory ideals. The ambiguity and contested nature, however, does not necessarily make these concepts irrelevant. Otherwise, we could argue that many other normative concepts, including media freedom and democracy, have also become irrelevant mantras.

As an open-ended aspirational ideal, the meaning of pluralistic and diverse journalism requires continued discussion and rethinking in the contemporary media environment. Despite the many dimensions and levels of analysis, I argue that the fundamental concern that remains at the core of these debates, even if it is not always recognized, is with the distribution of communicative power in society and the public sphere (see Baker 2007; Karppinen 2013).

Instead of consumer choice or celebration of new technologies, tools or content options as such, concerns over pluralism and diversity in journalism are centrally about challenging existing structural asymmetries in communicative power and supporting journalistic institutions' and practices' openness to new voices and actors. If pluralism is to serve as a critical concept in the context of journalism, we must then be able to distinguish the sheer number of voices, 
differences between these voices, and above all their relationship with existing power structures in society. As a consequence, pluralism in journalism can be understood to be more about power relations and less about counting the number of content options or outlets.

Of course, the institutionalization and realization of "a fair distribution of communicative power" itself is inevitably a contested aim. Like many other normative ideals, it is not an ideal that can ever be finally achieved. Despite the new opportunities offered by new technologies, the public sphere continues to be characterized by structural inequalities in the distribution of communicative power between individuals, social groups, corporations and states. From this perspective, pluralism is best conceptualized in terms of the contestation of hegemonic discourses and structures rather than as an ultimate solution or a state of affairs.

The implication of this for journalism is that journalists and journalism researchers should above all seek to recognize, and challenge, the existing hierarchies of power and the variety of factors that influence the access and representation of different social actors. In more concrete terms, such concerns relate to a number of issues, ranging from media ownership and the algorithmic power of new intermediaries to everyday newsroom practices and routines, such as the selection of sources and the framing of individual issues.

All of these issues remain important in their own right. Yet, pluralism and diversity are hardly concepts that provide a neutral yardstick that could be used to measure the performance of journalistic institutions with common normative criteria. As an ideal that can never be finally and unambiguously achieved, I argue that the notion of pluralism in journalism best serves an open-ended ideal 
that raises a series of problems regarding the role of journalism in the distribution of power and voice in society. 


\section{References}

Aslama Horowitz, Minna \& Philip M. Napoli. 2014. Diversity 2.0. A framework for audience participation in assessing media systems. Interactions: Studies in Communication and Culture 5(3). 309-326.

Baker, C. Edwin. 2007. Media Concentration and Democracy: Why ownership matters. Cambridge: Cambridge University Press.

Benson, Rodney. 2013. Shaping Immigration News: A French-American Comparison. Cambridge: Cambridge University Press

Boczkowski, Pablo J. 2010. News at Work. Imitation in an Age of Information Abundance. Chicago: Chicago University Press.

Carpentier. Nico \& Bart Cammaerts. 2006. Hegemony, Democracy, Agonism, and Journalism. An Interview with Chantal Mouffe. Journalism Studies 7(6). 964-975.

Castells, Manuel. 2009. Communication Power. Oxford: Oxford University Press.

Christian, Clifford G., Theodore L. Glasser, Denis McQuail, Kaarle Nordenstreng \& Robert A. White. 2009. Normative Theories of the Media: Journalism in Democratic Societies. Urbana \& Chicago: University of Illinois Press.

Connolly, William. 1995. The Ethos of Pluralization. Minneapolis: Minnesota University Press.

Crowder, George. 1994. Pluralism and Liberalism. Political Studies 42(2). 293305.

Curran, James. 2002. Media and Power. London: Routledge. 
Curran, James, Natalie Fenton \& Des Freedman. 2013. Misunderstanding the Internet. London: Routledge.

Curran, James, Sharon Coen, Toril Aalberg, Kaori Hayashi, Paul K. Jones, Sergio Splendore, Stylianos Papathanassopoulos, David Rowe \& Rod Tiffen. 2013. Internet revolution revisited. A Comparative study of online news. Media, Culture \& Society 35(7). 880-897.

Dahl, Robert. 1956. A Preface to Democratic Theory. Chicago: The University of Chicago Press.

De Vreese, Claes, Frank Esser \& David Nicolas Hopmann. 2017. Comparing Political Journalism. London: Routledge.

Diakopoulos, Nicholas. 2014. Diversity in the Robot Reporter Newsroom. http://www.nickdiakopoulos.com/2014/07/16/diversity-in-the-robotreporter-newsroom/ (accessed 25 October 2016).

Diakopouolos, Nicholas. 2015. Algorithmic accountability. Journalistic investigation of computational power structures. Digital Journalism 3(3), $398-415$.

Dimitrova, Daniela V. and Jesper Strömbäck. 2009. Look Who’s Talking. Use of sources in newspaper coverage in Sweden and the United States. Journalism Practice 3(1). 75-91.

Fenton, Natalie (ed.) 2010. New Media, Old News. Journalism and Democracy in the Digital Age. London: Sage.

Fraser, Nancy. 1992. Rethinking the Public Sphere: A Contribution to the Critique of Actually Existing Democracy. In Craig Calhoun (ed.), Habermas and the Public Sphere, 108-142. Cambridge: MIT Press.

Freedman, Des. 2008. The Politics of Media Policy. Cambridge: Polity Press. 
Freedman, Des. 2014. The Contradictions of Media Power. London: Bloomsbury.

Gibbons, Thomas. 2015. Active Pluralism: Dialogue and Engagement as Basic Media Policy Principles. International Journal of Communication 9. http://ijoc.org/index.php/ijoc/article/view/2762/1371 (accessed 25 October 2016).

Glasser, Theodore, Isabel Awad \& John W. Kim. 2009. The Claims of Multiculturalism and Journalism's Promise of Diversity. Journal of Communication 59(1). 57-78.

Habermas, Jürgen. 1989. The Structural Transformation of the Public Sphere. Cambridge: Polity Press.

Habermas. Jürgen. 2006. Political communication in media society: does democracy still enjoy an epistemic dimension? The impact of normative theory on empirical research. Communication Theory 16(4). 411-426.

Helberger, Natali. 2011. Diversity by design. Journal of Information Policy 1(1). $441-469$

Helberger, Natali. 2012. Exposure diversity as a policy goal. Journal of Media Law 4(1). 65-92.

Hindman, Matthew. 2009. The Myth of Digital Democracy. Princeton: Princeton University Press.

Hitchens, Lesley. 2006. Broadcasting Pluralism and Diversity: A Comparative Study of Policy and Regulation. Oxford: Hart Publishing.

Karppinen, Kari. 2013. Rethinking Media Pluralism. New York: Fordham University Press. 
Karppinen, Kari. 2015. The limits of empirical indicators. In Peggy Valcke, Miklos Sükösd \& Robert Picard (eds.), Media Pluralism and Diversity. Concepts, Risks and Global Trends, 287-296. Basingstoke: Palgrave Macmillan. Keane, John. 1999. On Communicative Abundance (CSD Perspectives). London: University of Westminster Press.

McChesney, Robert W. 2013. Digital Disconnect. How Capitalism in Turning the Internet against Democracy. New York: The New Press.

McLennan, Gregor. 1995. Pluralism. Buckingham: Open University Press. McNair, Brian. 2006. Cultural Chaos: Journalism, News and Power in a Globalised World. London: Routledge.

McQuail, Denis. 2007. Revisiting Diversity as a Media Policy Goal. In Werner A. Meier \& Josef Trappel (eds.), Power, Performance and Politics: Media Policy in Europe, 41-58. Nomos: Baden-Baden.

Mouffe, Chantal. 2005. On the Political. Abingdon \& New York: Routledge.

Napoli, Philip M. 1999. Deconstructing the Diversity Principle. Journal of Communication 49(4). 7-34.

Napoli, Philip M. 2011. Exposure diversity reconsidered. Journal of Information Policy 1. 246-259.

Napoli, Philip M. 2015. Social media and the public interest: Governance of news platforms in the realm of individual and algorithmic gatekeepers. Telecommunications Policy 39(9). 751-760.

Pariser, Eli. 2011. The Filter Bubble: What the Internet is Hiding from You. New York: Penguin Books.

Picard, Robert G. \& Cinzia dal Zotto. 2015. The Dimension of Ownership and Control of Media. In Peggy Valcke, Miklos Sükösd \& Robert Picard (eds.), 
Media Pluralism and Diversity: Concepts, Risks and Global Trends, 54-66. Basingstoke: Palgrave Macmillan.

Pollock, John. 2013 (ed.). Media and Social Inequality. Innovations in Community Structure Research. London and New York: Routledge.

Raeijmaekers, Danielle \& Pieter Maeseele. 2015. Media, pluralism and democracy: What's in a name. Media, Culture \& Society 37(7). 1042-1059.

Raeijmaekers, Danielle \& Pieter Maeseele. 2016. In objectivity we trust? Pluralism, consensus, and ideology in journalism studies. Journalism, published online ahead of print, doi: 10.1177/1464884915614244

Sjøvaag, Helle. 2016. Media diversity and the global superplayers: operationalising pluralism for a digital media market. Journal of Media Business Studies 13(3). 170-186.

Sunstein, Cass. 2007. Republic.com 2.0. Princeton: Princeton University Press. Valcke, Peggy, Miklos Sükösd \& Robert Picard (eds.). 2015. Media Pluralism and Diversity: Concepts, Risks and Global Trends. Basingstoke: Palgrave Macmillan.

van Cuilenburg, Jan. 1998. Diversity revisited: Towards a critical rational model of media diversity. In Kees Brants, Joke Hermes \& Liesbet van Zoonen (eds.), Media in Question, 38-49. London: Sage.

van der Haak, Bregtje, Michael Parks \& Manuel Castells. 2012. The future of journalism: networked journalism. International Journal of Communication 6. 2923-2938.

Vos, Tim P. \& François Heinderyckx (eds.). 2015. Gatekeeping in Transition. New York: Routledge. 
Wenman, Mark. 2013. Agonistic democracy. Constituent Power in the Era of Globalisation. Cambridge: Cambridge University Press. 